\title{
O impacto e a dimensão psicológica da doença trofoblástica gestacional: um estudo de
} caso

The impact and psychological position of gestational trophoblastic disease: a case study

El impacto y la posición psicológica de la enfermedad trofoblástica gestacional: un estudio de caso

Recebido: 20/03/2018

Aprovado: 15/09/2018

Publicado: 05/112018
Gabriela Souza Granero ${ }^{1}$ Irma Helena Ferreira Benate Bonfim² Álvaro da Silva Santos ${ }^{3}$

Este é um estudo de caso realizado numa cidade do interior de São Paulo em 2015, com o objetivo de compreender o impacto emocional e o enfrentamento de uma paciente em gestação trofoblástica. Utilizou-se entrevista não diretiva com caráter terapêutico e, a interpretação dos dados se deu pela análise de conteúdo temática. Evidenciou-se duas categorias: "Processo de luto" e, "O desequilíbrio psíquico e seus sintomas". Verificou-se sofrimento subjetivo e, o quanto uma complicação na gestação conjuntamente com aspectos pessoais relacionados à história de vida (vários processos de luto) fragilizaram a paciente. Porém houve resgate da sua saúde mental através de acompanhamento psiquiátrico e psicológico. Em si, os cuidados profissionais promoveram a elaboração, levando a resiliência, com isso, o reequilíbrio psíquico.

Descritores: Gravidez de alto risco; Estresse psicológico; Aborto espontâneo; Luto; Psicanálise.

This is a case study carried out in a city in the countryside of São Paulo, SP, Brazil in 2015 with the objective of understanding the emotional impact and the coping of a patient who experienced a trophoblastic pregnancy. A non-directive interview with a therapeutic character was used in the study and the interpretation of the data was made through thematic content analysis. There were two categories: "The mourning process" and "The psychic imbalance and its symptoms". Subjective suffering was observed, as well as the extent to which a complication during pregnancy together with personal aspects related to the life history (various processes of mourning) had shaken the patient. However, there was a recovery of her mental health through psychiatric and psychological follow-up. The professional care promoted the understanding, leading to resilience and, consequently, recovering the psychic balance.

Descriptors: High risk pregnancy; Psychological stress; Spontaneous abortion; Bereveament; Psychoanalysis.

Este es un estudio de caso realizado en una ciudad del interior de São Paulo, SP, Brasil en 2015, con el objetivo de comprender el impacto emocional y el enfrentamiento de una paciente en gestación trofoblástica. Se utilizó una entrevista no directiva con carácter terapéutico y, la interpretación de los datos se dio por el análisis de contenido temático. Se evidenció dos categorías: "Proceso de luto" y, "El desequilibrio psíquico y sus síntomas." Se verificó sufrimiento subjetivo y, el cómo una complicación en la gestación conjuntamente con aspectos personales relacionados a la historia de vida (varios procesos de luto) fragilizaron a la paciente. Sin embargo, hubo rescate de su salud mental a través de acompañamiento psiquiátrico y psicológico. En sí, los cuidados profesionales promovieron la elaboración, llevando la resistencia, con eso, el reequilibrio psíquico.

Descriptores: Embarazo de alto riesgo, Estrés psicológico; Aborto espontáneo; Aflicción; Psicoanálisis.

1. Psicóloga. Especializanda em Psicanálise pelo Centro Universitário Municipal de Franca (UNI-FACEF). Mestranda em Psicologia pela Universidade Federal do Triângulo Mineiro (UFTM), Uberaba, MG, Brasil. ORCID: 0000-0003-2612-5461 E-mail: gabrielagranero.gg@gmail.com

2. Psicóloga. Especialista em Psicanálise de Criança. Especialista em Psicodinâmica Familiar. Mestre em Promoção da Saúde. Doutora em Psicologia. Docente do UNI-FACEF, Franca, SP, Brasil. ORCID: 0000-0001-6863-7567 E-mail: irma@benate.com.br 3. Enfermeiro. Especialista em Saúde Pública. Especializando em Psicanálise pelo Núcleo de Pesquisas Psicanalíticas. Mestre em Administração em Serviços de Saúde. Doutor em Ciências Sociais (Antropologia). Pós Doutor em Serviço Social. Professor Associado do Programa de Pós-Graduação em Psicologia e do Programa de Pós-Graduação em Atenção à Saúde da UFTM. ORCID: 0000-0002-8698-5650 E-mail: alvaroenf@hotmail.com 


\section{INTRODUÇÃO}

A $\mathrm{s}$ doenças trofoblásticas gestacionais constituem um grupo de doenças da placenta conhecidas como mola hidatiforme. A mola hidatiforme (MH) é uma complicação da gravidez com potencial da evolução para doença com comportamento maligno e que ocorre, no Ocidente numa proporção de um caso para 1.000 a 2.000 gestações"1. Um estudo brasileiro, com base em atendimento hospitalar em um único centro, indica a proporção de 1 mola hidatiforme para 215 gestações ${ }^{1}$.

São reconhecidos dois tipos de $\mathrm{MH}$ : completa (MHC) e parcial ou incompleta (MHP). Elas se diferem quanto aos aspectos morfológicos (macroscópicos), histopatologia e cariótipo. Estas anomalias cromossômicas causam a perda precoce do embrião e proliferação excessiva do tecido trofoblástico, na mola hidatiforme completa - o óvulo não tem núcleo ativo, portanto os genes são de origem paterna e há ausência de feto.

Na MHP ocorre à presença do embrião que normalmente é inviável ou apresenta várias malformações, sendo resultado da fecundação de um ovócito secundário normal, por dois espermatozóides ou um espermatozoidediploide ${ }^{1}$.

A gravidez molar inicia, normalmente, com os sinais de uma gestação normal, no entanto, o sintoma mais comum é a presença de sangramento transvaginal, na forma de secreção escura ${ }^{2}$.

O diagnóstico é confirmado com a ultrassonografia que mostra o útero preenchido por pequenas áreas redondas, escuras, que lembram cacho-de-uva, na mola hidatiforme completa, e na mola hidatiforme parcial a placenta se apresenta espessada com saco gestacional e/ou embrião, vivo ou morto. Confirmado o diagnóstico, o útero deve ser esvaziado o quanto antes, através de um procedimento cirúrgico, sob anestesia geral ${ }^{2}$.

Após o esvaziamento uterino, $80 \%$ das pacientes com mola completa e $95 \%$ daquelas com mola parcial evoluirão para a cura sem a necessidade de nenhum outro tratamento ${ }^{2}$.

Entretanto, a porcentagem restante não terá normalizados os níveis de hCG, tornando necessário outros tratamentos para prevenir consequências mais sérias, o problema é quando o tecido placentário anormal torna a crescer, deste modo pode-se dizer que a paciente desenvolveu uma neoplasia trofoblástica gestacional ${ }^{2}$.

A mulher com gravidez molar deve ir periodicamente ao serviço de saúde para ser examinada com vistas à conhecer evolução ou remissão espontânea ou se vai precisar de tratamento para conseguir a cura (remissão pós-tratamento) ${ }^{2}$.

Durante o seguimento espera-se que a paciente não engravide, pois não será fácil diferenciar a nova gravidez da evolução para a neoplasia trofoblástica. Níveis persistentes ou crescentes de hCG, é indicativo de tecido trofoblástico persistente e de que ocorreu a transformação maligna desse trofoblasto, ou seja, a neoplasia trofoblástica gestacional ${ }^{2}$.

Esta neoplasia pode ser do tipo mola invasora, coriocarcinoma, tumor trofoblástico do sítio placentário e o tumor trofoblástico epitelióide, feito os exames, o médico vai estadiar a neoplasia e caracterizá-la ${ }^{2}$.

Com relação à quimioterapia é impossível predizer o número total de ciclos, pois varia de acordo com cada paciente baseado em vários fatores.

Após completar o tempo de acompanhamento (seis meses de dosagens normais de hCG nos casos de remissão espontânea e de doze meses de dosagens normais de hCG após o término da quimioterapia), a mulher poderá engravidar se assim o desejar, no entanto existe, uma possibilidade muito pequena, de risco em 1 a $2 \%$ de que ocorra nova gestação molar ${ }^{2}$.

Na dimensão psicológica, nota-se que o sofrimento psíquico é inevitável já que todas as condições biopsíquicas indicam a possibilidade de estar grávida, porém após o diagnóstico de mola a mulher se vê diante de uma doença complexa, sujeita a uma evolução com potencial maligno, tendo que passar por procedimento cirúrgico e lidar com a perda do bebê real ou fantasiado.

O diagnóstico de mola ocasiona um grande impacto para a mulher e seus familiares, por ser uma doença grave, de baixa incidência na população e desconhecida. Essas mulheres que recebem o diagnóstico de 
uma gravidez molar, submetem-se ao estresse da perda da gravidez, do procedimento cirúrgico, possível tratamento com quimioterapia e atrasos no plano reprodutivo até a remissão completa ${ }^{3}$.

A gravidez molar pode ocasionar um impacto no estado emocional, na vida sexual, reprodutiva e na qualidade de vida da mulher, desencadeando em alguns casos, quadros depressivos, por isso a intervenção psicológica é necessário, pois contribui para o enfrentamento e compreensão do diagnóstico e tratamento, assim como, na elaboração do enlutamento gestacional, diminuindo o nível de ansiedade, estresse, medos e fantasias das pacientes frente à doença ${ }^{3}$.

Considerando a carência de estudos na dimensão psicológica este estudo tem como objetivo compreender o impacto emocional e o enfrentamento de uma paciente frente à gestação trofoblástica.

\section{MÉTODO}

Trata-se de um estudo de caso com abordagem qualitativa, que se constitui em um meio para entender e explorar o significado que um indivíduo atribui a um problema social e humano ${ }^{4}$.

Os métodos qualitativos consideram a subjetividade do participante e do pesquisador, as impressões, atitudes, irritações; todos esses aspectos tornam-se dados e constitui-se parte da interpretação ${ }^{5}$.

Com relação à estratégia de investigação utilizada será: um estudo de caso único, da qual permite a exploração profunda de um indivíduo ${ }^{4}$. A escolha do caso é feita pelo próprio pesquisador por meio de atributos considerados importantes para o estudo ${ }^{6}$.

A pesquisa foi desenvolvida no segundo semestre de 2015, com uma paciente num ambulatório de especialidades de uma cidade do interior de São Paulo, através de entrevista semiestruturada previamente marcada e feita no próprio serviço de saúde.

Seguiu-se as orientações da Resolução no 466, de 12/12/2012 e, a pesquisanda recebeu nome fictício para sua proteção.

Os dados foram analisados em profundidade através da técnica análise de conteúdo temático ${ }^{7}$, na qual a primeira etapa denomina-se pré-análise, e realizou-se a leitura flutuante do material, para familiarização.

A próxima etapa denominada de análise dos dados constitui-se na: exploração do material, tratamento (categorização/ subcategorização), e posteriormente a apresentação e interpretação dos resultados, na qual visou-se atingir uma compreensão mais aprofundada dos conteúdos das mensagens ${ }^{7}$.

\section{RESULTADOS}

A participante "Valentina" tinha 30 anos, casada, com 2 filhos, usuária do Serviço de Atendimento de Gestante de Alto Risco em uma cidade do interior de São Paulo, na qual faz tratamento nesse ambulatório devido à ocorrência de uma doença trofoblástica gestacional do tipo mola hidatiforme completa.

Num primeiro momento a participante explicitou o motivo pelo qual ela fora encaminhada ao ambulatório:

Estou fazendo um tratamento que terá a duração de um ano, tive uma gestação molar e eu desejo engravidar de novo, mas antes preciso fazer esse tratamento.

0 motivo do não prosseguimento da sua gestação fruto da ocorrência de uma gestação molar, e seu histórico com relação as suas gestações anteriores:

Antes da gestação molar, tive uma gravidez ectópica e como consequência tive que retirar uma trompa, passei por um procedimento de curetagem para retirar o feto, nessa mesma época a minha sogra faleceu e logo em seguida meu cunhado que era usuário de drogas, ele também morreu. Depois do falecimento da minha sogra, acredito que meu cunhado sentiu muita falta dela e ai começou a mexer ainda mais com drogas, e faleceu durante uma briga na rua, sabe, foi muito triste...

A paciente informou também que três perdas próximas haviam ocorrido: a gestação, o falecimento da sogra e do cunhado.

Com relação ao luto gestacional, fora perguntado a se ela externalizou seus sentimentos com o marido sobre a perda do bebê:

Ah não comentei nada sabe por quê? O meu marido estava muito abalado com a perda da mãe e do irmão também, não queria causar mais dor, ele já estava bem triste, então nem ficava falando pra ele que pra mim foi difícil perder o bebê.(...) Quando eu perdi meu bebê me colocaram junto com as mães que tinham acabado de ganhar, achei um descuido muito grande do hospital fazer isso com as pessoas, colocar as mães que perderam 
seus filhos junto com a maternidade, quando ouvia um choro da criança, dava vontade de chorar junto.

Sob a descoberta do diagnóstico, a mesma respondeu:

Fui fazer os exames, e trouxe meus dois filhos, queria que eles vissem o ultrassom, mas durante a consulta a médica me disseram que tinham que ser encaminhada as pressas para o hospital e que teria que tirar ofeto, as trompas $e$ o útero, eu nem sabia o motivo, meu mundo desabou, comecei a chorar desesperadamente e meus filhos, coitados, ficaram muitos assustados, deixei eles em casa e fui direto pro hospital. Quando cheguei ao hospital, o médico veio com anestesia, meu medo era tão grande, mas tão grande, que eu não o deixava aplicar a anestesia, ai colocaram um calmante no soro, o que fez com que eu perdesse as forças, fiquei molinha, ai sim aplicaram a anestesia.

Valentina comentou sobre a última frase dita ao médico:

Não me deixe morrer, e aí depois que eu acordei da cirurgia pedi pra ver o meu bebê, o que eles tinham tirado. Ao ser perguntado o que ela vira, ela responde: ah não era um bebê formado sabe, não tinha um rostinho, nada, eu vi várias molinhas, sabe, várias molas, como se fosse um cacho de uva. (...) Esse susto que levei aconteceu no terceiro mês, e graças a Deus os médicos disseram que não tiveram que tirar o útero e nem as trompa, e lá no hospital todo mundo, os residentes queriam saber do meu caso, pois disseram que tinha uma doença rara, que ocorre uma em cada mil...

Ao ser questionada como ela se sentiu após esse "susto", ela relatou:

Então, depois de tudo isso que aconteceu, comecei a ter depressão, eu não dormia de noite, quando eu assistia algum noticiário em que os pais matavam os filhos, eu ficava a noite inteira acordada achando que meu marido ia matar meus filhos, ou quando eu via uma aranha na Tv começava a achar que ela era real, você acredita que fiquei oito dias sem dormir, mas essas coisas eu só sentia de noite, sabe, de dia até que ficava bem. (...) Depois comecei a tomar os remédios, Clonazepam e Sertralina, $e$ consegui voltar a dormir, e fui encaminhada para a psicoterapia, hoje faz cinco meses que estou indo na terapia uma vez por semana, agora eu estou beeem melhor. Só tem uma coisa eu não sinto vontade de ter relação sexual com meu marido, sabe, eu acho que como eu fiz muitas curetagem meu útero ficou muito sensível e eu não sei por que não tenho mais desejo, mas deve ser por causa isso...

Apesar desses acontecimentos, a paciente ainda nutria o desejo de ter outro filho, dizendo:

Eu ainda quero engravidar de novo, tentar mais uma vez, nas minhas outras gestações, meus filhos já havia até escolhido os nomes do bebê.

Ao ser perguntada como que a psicoterapia poderia ajudá-la a enfrentar esses momentos difíceis, ela respondeu:
Então eu saia mais leve, menos angustiada e menos confusa, sabe, eu até tinha vontade de conversar mais com minha mãe, contar meus problemas para ela, mas eu não quero deixar ela preocupa e com o psicólogo é diferente sei que posso jogar tudo em cima dele, mas sabe eu estou sentindo vontade de parar de tomar remédio $e$ para com a terapia também, já me sinto bem melhor.

Ao término da entrevista Valentina pontuou que os acontecimentos a tornaram uma pessoa amadurecida, dando um sorriso.

\section{DISCUSSÃO}

Duas categorias temáticas a partir das falas se evidenciaram, a saber: "Processo de luto" e, "O desequilíbrio psíquico e seus sintomas".

$\mathrm{Na}$ primeira categoria o "Processo de luto" vivenciado pela gestante, ficou evidente o quanto o processo de elaboração de perda é complexo e doloroso. É comum após um óbito fetal, a falta de incentivo aos pais a falarem sobre o que aconteceu, e a ausência de recordações do filho, provocando uma sensação de irrealidade e vazio ${ }^{8}$.

Pelo fato de Valentina não ter tido com quem compartilhar o luto, não houve um espaço para a elaboração e externalização de sua dor. É importante encorajar o enlutado oferecendo apoio emocional e permitindo que essas pessoas que passaram por perdas expressem livremente seus sentimentos, pois quando não há espaço para elaboração, o luto mal resolvido pode manifestar momentos de raiva, melancolia e episódio de forte emoção ao se lembrar da perda?.

Pelo fato do luto ser uma experiência subjetiva, as famílias enlutadas precisam ser acolhidas, cuidadas e respeitadas em suas particularidades, e a elaboração de um luto só pode ser bem sucedida, se o enlutado tiver o apoio durante o tempo que necessitar, é preciso viver o sentimento de perda, respeitando seu próprio ritmo, só assim é possível recriar a realidade ${ }^{10}$.

A participante estava passando também por um processo de luto familiar (falecimento da sogra e do cunhado) e o processo decorrente de sua gestação interrompida, assim, ela estava vulnerável, e somado ao fato da gestante e seu marido não possuírem o apoio necessário, toda família também estava sofrendo. 
Quando o indivíduo em luto está próximo das pessoas que amam e acolhem e compartilham seu sofrimento, ele é capaz de aceitar sua compaixão e restaurar a harmonia em seu mundo interior, sendo assim, seus medos e sua dor se reduz com maior rapidez ${ }^{11}$. Embora o marido da participante compartilhasse da mesma dor, os dois estavam fragilizados e, emocionalmente desestabilizados.

A condição da mulher após um aborto espontâneo é de grande instabilidade emocional, desta forma, suportar a dor de ter perdido um filho em contraposição as gestantes que tiveram uma gestação bem sucedida é um trabalho árduo e doloroso, pois, tal experiência foi vivida como sendo uma exposição de sua dor e de seu "fracasso", devido ao não prosseguimento da gestação.

A perda do bebê é uma experiência emocional delicada e dolorosa e quando tais mulheres enlutadas se encontram numa maternidade rodeada por gestantes, puérperas e bebês recém-nascidos, para a mãe resta experimentar a sensação de sair da maternidade sem seu filho nos braços.

A incapacidade de ser mãe, tende a levar as mulheres a uma interpretação de um feminino inadequado, com sentimentos de fracasso, incompetência e um rebaixamento da autoestima, por tratar-se de um investimento afetivo, que termina abruptamente, pois expectativas, desejos, sonhos, fantasias existiam, muitas vezes antes da gravidez e nestes casos são frustradas bruscamente ${ }^{9}$.

Contudo, é preciso lembrar que dependendo do grau de investimento afetivo ocorrido durante a gravidez, maior será o sofrimento posterior à perda, e muitas mulheres relatam que ficam sem perspectivas, por isso, dizem que perder um dos pais é perder o passado, mas, perder um filho, é perder o futuro 9 .

O trabalho de elaboração do luto, consiste em um movimento psíquico delicado, pois nos casos de óbito fetal, o contato com o bebê real só é vislumbrado nas ultrassonografias, não tendo ocorrido o contato concreto, o que pode aumentar a dificuldade da elaboração do luto do filho imaginário.

Isto propicia uma situação contraditória evocada pelo intenso investimento psíquico durante a gravidez e imediato desinvestimento após o anúncio da morte, o que é perdido é o objeto virtual, vivido com muita ambivalência ${ }^{8}$.

A segunda categoria intitulada " $O$ desequilíbrio psíquico e seus sintomas", traz a compreensão da condição mental da paciente, diante de acontecimentos traumáticos.

É possível que a paciente tenha desenvolvido depressão com sintomas psicóticos, delírios e alucinação que vieram como uma defesa do ego e uma tentativa de elaboração das suas vivências, além disso, notou-se que os sintomas eram manifestados com maior intensidade durante a noite, por ser o período em que estímulos externos diminuíam e o silêncio proporcionava um momento de encontro subjetivo consigo mesma. A depressão é uma consequência comum em pacientes que passaram por abortos espontâneos ou provocados ${ }^{9}$.

A perda de um filho abre um "buraco", uma ferida narcísica que leva as mães para severos quadros melancólicos. É comum nos primeiros momentos, não querer sair da cama, nem mesmo para comer ou tomar banho ${ }^{14}$.

Diante da intensidade dos acontecimentos, a participante ficou incapacitada e com poucos recursos para lidar com inúmeras perdas e sofrimentos, mas com o tempo e a psicoterapia ela conseguiu se estabelecer.

Nem sempre os sintomas provocam consequências negativas, muitas vezes eles funcionam como uma defesa e um recurso do próprio ego para a elaboração de acontecimentos traumáticos.

A não aceitação do processo de luto, muitas vezes se arrasta por muito tempo, o que pode ocasionar algumas patologias, como a "melancolia", sinônimo central da depressão e, a não interiorização dos processos de perda faz com que a pessoa esteja presa à realidade passada ${ }^{15}$.

O luto é uma reação á perda e não uma condição patológica, de modo que pode ser 
superado após um lapso de tempo. Entretanto, em algumas pessoas as mesmas influências podem produzir a melancolia, o que pode significar que tais pessoas possuem uma pré-disposição patológica à depressão ${ }^{13}$.

Os traços mentais da melancolia são: desânimo profundamente doloroso, suspensão de interesse pelo mundo externo, perda da capacidade de amar, inibição de toda e qualquer atividade e, diminuição dos sentimentos de autoestima a ponto de encontrar expressão em autorrecriminação, autoinsultos, autocríticas, culminando numa expectativa delirante de punição ${ }^{13}$.

No luto é o mundo que se tornou pobre e vazio; já na melancolia é o próprio ego que está empobrecido ${ }^{13}$.

A criatividade é importante nas elaborações do luto, só por meio dela é possível ressignificar a perda e seus sentimentos ${ }^{10}$.

0 uso da criatividade conjuntamente com o apoio familiar e social permitem que a realidade possa ser suportada, de forma que a dor não comprometa sua capacidade de dar continuidade à vida ${ }^{10}$.

Klein ${ }^{11}$ destaca que quando o sofrimento é vivido ao máximo e o desespero atinge seu auge, o indivíduo vê brotar novamente seu amor pelo objeto, e descobre que o objeto amado pode ser conservado em seu interior.

Nesse estágio do luto, o sofrimento torna-se produtivo, pois experiências dolorosas estimulam a sublimação, e muitas vezes despertam novas habilidades, como: começar a pintar, escrever ${ }^{11}$.

Já outras pessoas manifestam sua criatividade de outra forma, ampliando sua capacidade de apreciar a realidade, tornandose pessoas mais sábias e tolerantes na sua relação com os outros.

Pode-se observar que após Valentina passar por um tratamento psiquiátrico $\mathrm{e}$ psicoterapêutico seus sintomas foram minimizados reencontrando seu equilíbrio mental.

A psicanálise pode então, oferecer um lugar de escuta ao sofrimento da mãe que perdeu o filho, para que ela não recaia completamente no lugar de vítima, mas sim que ofereça continência para sua dor e promova um encontro com seus recursos internos de modo que ela possa fazer um "giro" da morte em direção à vida ${ }^{15}$.

Mas para isso é necessário paciência, pois trata-se de um trabalho delicado, de longo prazo e que envolve escuta afetiva das suas vivências de morte ${ }^{15}$. Neste contexto, pode-se pensar que é acolhendo suas vivências, identificando e elaborando seus assombros, que a paciente, se estrutura e retoma o investimento de retorno a vida.

\section{CONCLUSÃO}

A paciente em questão passou por uma série de lutos, com dois abortos espontâneos, um ocasionado pela gravidez ectópica e o outro por uma gestação molar, além de dois lutos familiares (sua sogra e o cunhado). Estas perdas culminaram num desequilíbrio psíquico.

As elaborações resultaram em um luto patológico, principalmente pelas ausências de tempo para elaborar tantas perdas, além do que do desejo de ter outro filho, com vistas a romper com o vazio deixado por uma gestação não concretizada e por mais um sonho fracassado.

A atenção psiquiátrica e psicoterapêutica fora essencial nesse momento crítico, envolto por duras perdas e situações desestruturantes.

Por se tratar de um estudo de caso único, não é possível generalizar os resultados, pois o enfrentamento de outras gestantes diante de situações como essas pode ser diferente, sendo assim, sugere-se que em pesquisas posteriores ampliem-se para pesquisas tanto quantitativas como qualitativas na temática.

No entanto, este estudo traz uma contribuição num cenário carente de trabalhos que relacionem aspectos psicológicos vivenciados por mulheres com gestações molares.

\section{REFERÊNCIAS}

1. Andrade JMD. Mola hidatiforme e doença trofoblástica gestacional. Rev bras ginecol Obstet. 2009; 31(2):94-101.

2. Sociedade Brasileira de Doença Trofoblástica Gestacional. Mola: manual de informações sobre doença trofoblástica gestacional. 2014. p.1-12. 
3. Lima CMD, Lopes MH, Vieira MJN, Simonetti PRD. Atendimento psicológico às mulheres com gestação molar. In: Congresso dos profissionais das universidades estaduais de São Paulo; 2011; São Paulo. São Paulo: USP; 2011.1p.

4. Creswell, JW. Projeto de pesquisa: métodos qualitativo, quantitativo e misto. 3ed. Porto Alegre: Artmed; 2010.

5. Flick U. Introdução a pesquisa qualitativa. 3ed. Porto Alegre: Artmed; 2009.

6. Stake RE. Case studies. In: Denzin NK, Lincoln YS. Handbook of qualitative research. London: Sage Publications; 2000. p. 435-454.

7. Turato ER. Tratado da metodologia da pesquisa clínico-qualitativa: construção teóricoepistemológica, discussão comparada e aplicação nas áreas da saúde e humanas. 6ed. Rio de janeiro: Vozes; 2013.

8. Aguiar HC, Zornig S. Luto fetal: a interrupção de uma promessa. Estilos Clín. [Internet]. 2016 [citado em 02 fev 2018]; 21(2):264-81. Disponível em:

http://pepsic.bvsalud.org/scielo.php?script=sci_a rttext\&pid=S1415-71282016000200001

9. Assunção AT, Tocci HA. Repercussão emocional do aborto espontâneo. Rev Enferm UNISA. 2003; 4(1):5-12.

10.Andrade ML, Mishima-Gomes FKT, Barbieri V. Recriando a vida: o luto das mães e a experiência materna. Psicol Teor Prát. [internet]. 2017; 19(1):21-32. [citado em 02 fev 2018]. Disponível em:http://pepsic.bvsalud.org/scielo.php?script=s ci_abstract\&pid=S1516-36872017000100002

\section{Granero GS, Bonfim IHFB, Santos AS}

\section{Dimensão Psicológica}

11. Klein M. Amor, culpa e reparação e outros trabalhos (1921-1945). Rio de Janeiro: Imago; 1996.

12. Lemos LFS, Cunha ACB. Concepções sobre a morte e luto: experiência feminina sobre a perda gestacional. Psicol Ciênc Prof. [Internet] 2015 [citado em: 03 fev 2018]; 35(4):1120-38. Disponível

em:http://www.scielo.br/scielo.php?pid=S141498932015000401120\&script=sci_abstract\&tlng= pt

13. Carone M, Freud S. 1985: luto e melancolia. J Psicanál. 2016; 49(90):207-24.

14. Cremasco MVF, Schinemann D, Pimenta SO. Mães que perderam filhos: uma leitura psicanalítica do filme Rabbit Hole. Psicol Ciênc Prof. [Internet]. 2015 [citado em: 03 fev 2018]; 35(1):54-68.

Disponível em:http://www.scielo.br/scielo.php?pid=S141498932015000100054\&script=sci_abstract\&tlng= pt

15. Taverna G, Souza W. O luto e suas realidades humanas diante da perda e do sofrimento. Cad Teol PUC-PR. 2014; 02(1):38-55.

CONTRIBUIÇÕES
Gabriela Souza Granero foi responsável pelo
desenho do estudo, coleta de dados, análise e
redação. Irma Helena Ferreira Benate Bonfim
participou naorientação do estudo e revisão do
artigo. Álvaro da Silva Santos atuou na redação e
revisão do artigo.

\section{Como citar este artigo (Vancouver)}

Granero GS, Bonfim IHFB, Santos AS. O impacto e a dimensão psicológica da doença troflobástica gestacional: um estudo de caso. REFACS [Internet]. 2018 [citado em: inserir dia, mês e ano de acesso]; 6(4):801-807. Disponível em: inserir link de acesso. DOI: inserir link do DOI.

\section{Como citar este artigo (ABNT)}

GRANERO, G. S.; BONFIM, I. H. F. B.; SANTOS, A. S. O impacto e a dimensão psicológica da doença trofoblástica gestacional: um estudo de caso. REFACS, Uberaba, MG, v. 6, n. 4, p. 801-807, 2018. Disponível em: <inserir link de acesso>. Acesso em: inserir dia, mês e ano de acesso. DOI: inserir link do DOI.

\section{Como citar este artigo (APA)}

Granero, G.S, Bonfim, I.H.F.B \& Santos, A.S. (2018). O impacto e a dimensão psicológica da doença trofoblástica gestacional: um estudo de caso REFACS, 6(4), 801-807. Recuperado em: inserir dia, mês e ano de acesso de inserir link de acesso. DOI: inserir link do DOI. 